\section{OPTIMAL ACCURACY PERFORMANCE IN MUSIC-BASED EEG SIGNAL USING MATTHEW CORRELATION COEFFICIENT ADVANCED (MCCA)}

\author{
Mahfuzah Mustafaa, Zarith Liyana Zaharia,b*, Rafiuddin \\ Abdubrania
}

aFaculty of Electrical and Electronics Engineering Technology, University Malaysia Pahang (UMP), Malaysia

bElectronic Engineering Division, Engineering Campus, UniKL BMI, Malaysia
Article history

Received

22 March 2021

Received in revised form

23 August 2021

Accepted

2 September 2021

Published Online

20 October 2021

*Corresponding author zarithliyana@unikl.edu.my

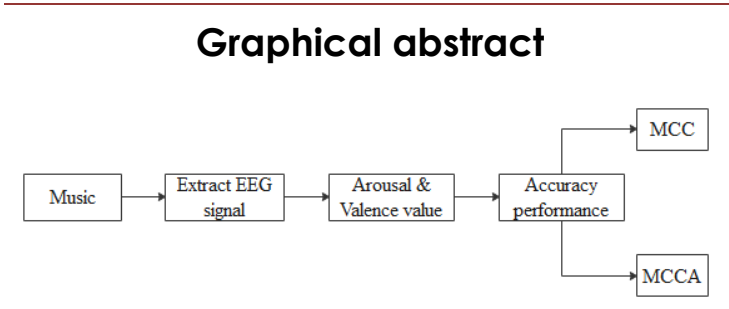

\begin{abstract}
The connection between music and human are very synonyms because music could reduce stress. The state of stress could be measured using EEG signal, an electroencephalogram (EEG) measurement which contains an arousal and valence index value. In previous studies, it is found that the Matthew Correlation Coefficient (MCC) performance accuracy is of $85 \pm 5 \%$. The arousal indicates strong emotion, and valence indicates positive and negative degree of emotion. Arousal and valence values could be used to measure the accuracy performance. This research focuses on the enhance MCC parameter equation based on arousal and valence values to perform the maximum accuracy percentage in the frequency domain and time-frequency domain analysis. Twenty-one features were used to improve the significance of feature extraction results and the investigated arousal and valence value. The substantial feature extraction involved alpha, beta, delta and theta frequency bands in measuring the arousal and valence index formula. Based on the results, the arousal and valance index is accepted to be applied as parameters in the MCC equations. However, in certain cases, the improvement of the MCC parameter is required to achieve a high accuracy percentage and this research proposed Matthew correlation coefficient advanced (MCCA) in order to improve the performance result by using a six sigma method. In conclusion, the MCCA equation is established to enhance the existing MCC parameter to improve the accuracy percentage up to $99.9 \%$ for the arousal and valence index.
\end{abstract}

Keywords: EEG, arousal index, valence index, accuracy, MCC and MCCA

\begin{abstract}
Abstrak
Hubungan antara muzik dan manusia sangat sinonim kerana muzik dapat mengurangkan keadaan tekanan. Keadaan tekanan dikesan menggunakan isyarat EEG. Pengukuran EEG mengandungi nilai arousal and valence indeks.Dalam kajian sebelumnya, prestasi ketepatan Matthew correlation coefficient (MCC) mampu mengahasilkan nilai julat dalam ukuran $85 \% \pm 5 \%$. Arousal menunjukkan sebagai kekuatan emosi, dan valence menunjukkan tahap emosi yang positif dan negatif. Nilai arousal and valence ini mampu mengenal pasti prestasi ketepatan. Penyelidikan ini memberi tumpuan kepada peningkatan persamaan
\end{abstract}


parameter MCC berdasarkan arousal and valence untuk melaksanakan peratusan ketepatan maksimum dalam domain frekuensi dan analisis domain frekuensi masa. Dua puluh satu ciri digunakan untuk meningkatkan kepentingan keputusan pengekstrakan ciri dan menyiasat nilai arousal and valence. Pengekstrakan ciri besar melibatkan alpha, beta, delta, dan theta frekuensi diperlukan untuk mengira formula indeks arousal and valence. Daripada keputusan ketepatan, indeks kebangkitan dan pelepasan boleh diterima untuk diguna pakai sebagai parameter dalam persamaan MCC. Namun begitu, dalam kes-kes tertentu, pengubahan parameter MCC diperlukan untuk mencapai peratusan ketepatan yang tinggi dan penyelidikan ini mencadangkan MCCA supaya dapat meningkatkan keputusan prestasi. Kesimpulannya, persamaan Matthew correlation coefficient advanced (MCCA) diwujudkan untuk meningkatkan parameter MCC sedia ada dan dapat meningkatkan peratusan ketepatan kepada $99.9 \%$ untuk indeks arousal and valence.

Kata kunci: Electroencephalogram (EEG), indeks arousal, indeks valence, Ketepatan, Matthew correlation coefficient (MCC) dan Matthew correlation coefficient advanced (MCCA)

(C) 2021 Penerbit UTM Press. All rights reserved

\subsection{INTRODUCTION}

Music is proven to be a valuable tool for understanding and underlying brain mechanisms. The underlying music mechanism which is part of human responses are physiological stress, behavior and emotion. In medical treatment, the form of music is used to provide therapeutic experiences or as one of the medical approaches for healing treatment [1]. Biomedical applications can be used in medical treatment related to human emotion and feeling because the signal prouces by EEG may recognize the emotional expressions such as anger, sadness, happiness, and love.

In general, it is possible to differentiate music in a variety of types and categories. Greenberg et al. classified music into two categories: empathizing and systemizing. The empathizing typed of music referred to the R\&B/soul, adult contemporary and soft rock. On the other hand, punk, heavy metal, and hard rock belong to the systemizing category [2]. The observation pleasant of Hindustani music in two ragas type "chayanat" and "Darbari Kannada" shows that this type of music is capable in influencing the human emotion and concentration [3]. In another music study by (in-text citation) which applied four types of music genres namely rap, metal, rock and hip hop. Based on this study, it is found that different music genre resulted in different performances The findings of the study highlighed that rock and rap may represent happy and sad emotion [4]. Apart from that, the implementation of music, also indicates various types of human emotions and their preferences. Hence, the signal brain performance is likely to be very subjective to describe because it depends on the individual music preference. Therefore, this study applied and focused on two music genres which are pop-punk and baby rhythm. These music genres are classified the Empathizing-
Systemizing (E-Z) type of music. The E-Z is used in this study mainly due to the abilities to identify, predict and respond appropriately to the mental states and behavior system [5]. Moreover, the pop-punk and baby rhythm are based on the expression of emotion and the stress condition. Additionally, pop-punk is usually used for signal investigation compare to baby rhythm. Both pop-punk and baby rhythm are chosen because these types of genres are used to differentiate the music and identify the respective EEG signal performances.

In signal processing, a bandpass filter in the EEG signal processing analysis is practically applied to obtain the EEG frequency range from $0.01 \mathrm{~Hz}$ until $100 \mathrm{~Hz}$ with an approximate amplitude of $100 \mu \mathrm{V}$. The bandpass filter can be an initial step in EEG signal processing. Bashar et al. (2016) used this technique to remove the noise and artefact containing the EEG signal for human identification biometric [6]. In addition, Li et al. (2016) also applied the bandpass technique in the communication system application. The bandpass filter ensures the optimal low and highfrequency spectrum according to the specific requirement in the system. The particular frequency range is for analyzing the amplitude, frequency, and phase parameter feature in EEG signals [7]. Another function of the bandpass filter is to perform the fraction bandpass filter stated by Baranowski et al. The fraction function consists of the classical and parallel fraction. The utilization of the fraction is able to optimize the filter parameter in a specific frequency [8]. Therefore, bandpass filter is used to remove the undesired frequency signal contained in the raw EEG signal.

Time domain, frequency domain, and timefrequency domain are the practical analysis domains used to interpret the EEG signal extraction features. The detailed explanation of extraction features is described in two different domains analysis of signal 
processing, which are frequency domain analysis and time-frequency domain analysis. The frequencydomain analysis focuses on the Power Spectral Density (PSD). In contrast, the time-frequency domain analysis focuses on Short Time Fourier Transform (STFT) and Continuous Wavelet Transform (CWT) method to describe the EEG signal features extraction.

The frequency-domain analysis is defined as spectral analysis. The spectral analysis is the most conventional approach in the frequency domain of the EEG signal. In standard practice, the frequency domain method in the EEG signal is Power Spectral Density (PSD). The PSD can be presented based on power distribution value of EEG signal for various evaluation purposes. Dhiya et al. applied the PSD method to analyze the power spectral density estimation and relative power containing Alzheimer's EEG signal. The coherence estimation and statistical function were obtained from the Alzheimer's EEG signal [9]. The cognitive process function is an effort to analyze the effectiveness of processing, manipulating, and interpreting EEG signals. Hence, the cognitive system is accepted in the utilization of the PSD method. The power value may be recognized in a particular set of frequency bands in the power spectral density system, such as a power peak value and mean value [10],[11],[12]. Dilber et al. (2017) calculated the power statistical feature to identify the performance of the EEG epilepsy data signal. The power value can be used as a primary value for finding a statistical feature which include the mean, standard deviation, and variance [13].

The Continuous Wavelet Transform (CWT) is one of the most popular methods to analyze the EEG complex signal. It also computes the Shannon entropy and probability distribution of the energy coefficient features for emotion recognition purposes [14]. Rojas et al. (2019), in a review on Wavelet Transform stated that several features can be obtained from the signal dataset's energy distribution, depending on the research function such as mean, variance, skewness, kurtosis, and RMS features which are counted as a reliable function in analyzing the EEG signal [15]. STFT is a practical method use to extract the features from the spectrogram in the time-frequency domain. RamosAguilar et al. applied this method to analyze the STFT spectrogram to find the minimum, maximum, and mean energy value on epilepsy EEG dataset patients [16]. The scalp region involved multiple electrode channels was used to collect the data which discriminated among several tasks. Therefore, CWT is applied in signal processing to eliminate a redundant signal to achieve better accuracy while STFT is a common method to classify multiple EEG signal representations. The STFT method for studying human identification emotion based on the EEG signal enables various features component such as mean, standard deviation, variance, covariance, mean absolute deviation, median absolute deviation, skewness, kurtosis, and peak to peak value of minimum, maximum, and median value to be obtained. The result of all the features stated becomes the input value to the classification method [17]. The elaboration of features in this study includes basic, extended, and advanced statistics that directly involved power and energy value in manipulating the statistical features. The basic features of extraction is are minimum, maximum, mean, standard deviation, root means square (RMS), standard deviation error, median, mean deviation, and coefficient mean deviation. The extended features are the capability of calculating variance, skew, and kurtosis. The Physiological Signal Databased (DEAP) analysed the statistical features to identify the inattentiveness of driver condition [18]. As an example, the statistical feature is a real value which are commonly used in the engineering application as a solution approch. Therefore, the desicion of statistical features is being contributed to the arousal and valence input paramater value to measure the MCC and MCCA.

Valence and arousal are two important parameters that are highly associated with emotional states. Arousal refers to a physiological activity dimension which range from quiet to active mood. It is also linked to the excitement level of an individual. Valence refers to another physiological activity dimensional orthogonal to arousal, with scope from misery to pleasant [19]. The arousal-valence emotion dimension is shown in Figure 1. The dimension model include the joy (valence positive + arousal high), distressed (valence negative + arousal high), depressed (valence negative + arousal low), and relaxed (valence positive + arousal low) [20].

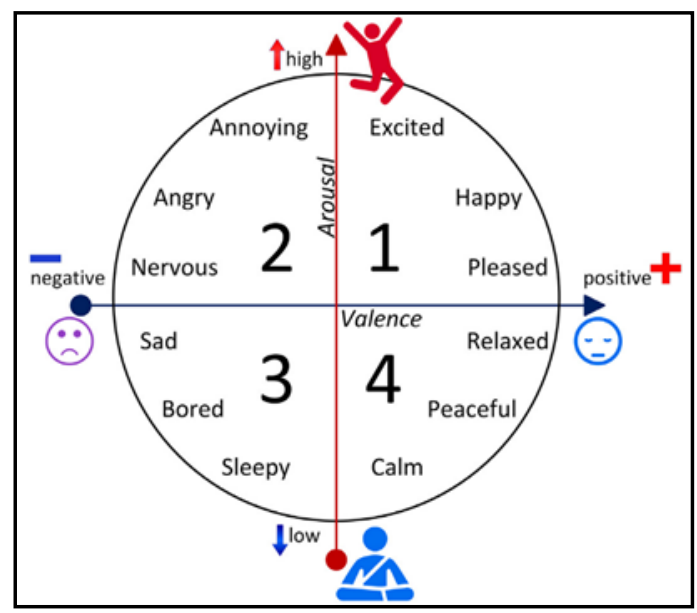

Figure 1 Arousal valence model dimension[20]

In physiological terms, the meaning of arousal is the point perception of sense and sensory responses, while valence is defined as the intrinsic attractiveness experiences. The visual, audio, and physiological signals such as the EEG signal are used as measurement elements in studying the affective and physiological response of arousal and valance. In regard to the mental health care treatment, both the 
valence and arousal elements of effect are important factors since they are correlated with affective and physiological responses. To evaluate the indication of positive and negative degree of emotion for arousal and valence in mental health care therapy, the central and peripheral nervous system from EEG signal need to be tested to prove the model arousal accuracy is $74.65 \%$ and valence accuracy is $78 \%$ [21]. The arousal and valence were known as instantaneous emotion indicators. The arousal indicates as strength of emotion, while valence indicates a positive and negative degree of emotion. These arousal and valence value are capable of identifying the accuracy performance. The strength of emotion describes the emotional intensity ranging from calm to activated emotion such as anger, sadness, happiness, and love, while the degree of positivity and negativity of emotion ranging from pleasant to unpleasant [22]. The EEG signal for emotion recognition with the high and low arousal and high and low valence state has performed the arousal in $82.11 \%$ and valence $82.03 \%$ using an artificial neural network classifier timefrequency domain conducted by Mert et al.(2018) [23]. It is an indication that there is a connection between human emotion and feeling which are measurable in music. Music has proven to be a valuable tool for understanding and underlying brain mechanisms. The underlying music mechanism is a part of the human response process to physiological stress and behavior, including emotion. The efficiency of physiological signal and features about music information retrieval (MIR) in EEG signal has been exploited. The relationship between the arousal and mood categories to reach $59.97 \%$ of arousal and $60.78 \%$ for mood as best performance result [24].

The EEG signal can also group the characteristics of brain activity with the use of the classification process. The classification function has recognized the group, class, type, or category in the largest data set. However, the EEG signal effect contains various signals depending on the situation or condition and classification required, including emotion recognition data. The arousal responses were $82.58 \%$ and valence $86.44 \%$ in the investigation on continuous music emotion recognition based on the EEG signal using the Matthews correlation coefficient (MCC) method. The MCC equation implementation handles the imbalanced data in a larger sample size [22]. Other than emotion, the MCC equation could identify alcoholism from the EEG signal because alcoholism affects the brain structures and functions. Therefore, the EEG signal recognizes the categories of alcoholic and non-alcoholic with the Matthews correlation coefficient of 0.9494 which was found by Patidar et al. (2017)[25]. The structure and brain condition of could be tested by measuring and analyzing the non-linear and non-stationary of EEG signal trends. The significance of measurement demonstrates the sensitivity, specificity, and MCC. The MCC shows a more balanced measure of classification with $96 \%$ accuracy [26]. The
Approximate entropy (ApEn), Sample Entropy (SampEn) and Reyni's entropy (RE) are the features use to analysed partial epilepsy in EEG signal in order to classify the Focal and Non-Focal categories present $96 \%$ as used by Arunkumar et al. (2017) [27].

This paper consists of four parts, which begins with introduction and followed by methodology. The methodology describes the signal processing for EEG signal. The investigation of signal processing was employed to obtain the result and discussion of MCC and MCCA based on music application in section 3. This paper ends with the summary of the reseach work presented as conclusions in section 4 .

\subsection{METHODOLOGY}

\section{Introduction}

This section describes the process to optimize accuracy using MCCA. Therefore, the MCCA is proposed to reach the accuracy percentage of $95 \%$ $+5 \%$ in frequency domain and time-frequency domain analysis. The research framework of this study serves as a guide in the attempt to solve the problem according to four main steps as presented in Figure 2. This critical component involves three-stages are EEG signal, signal processing, and features extraction. The next step is the mechanisms which was used to achieve the of the study for accuracy optimization, as shown in Figure 2.

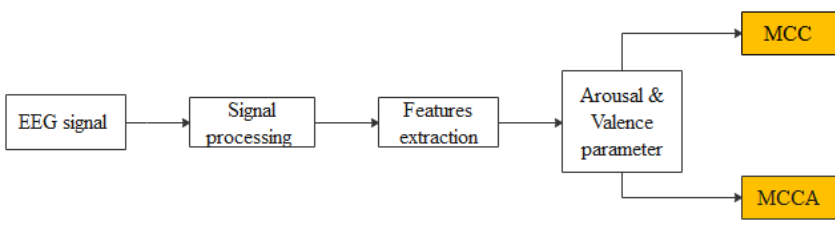

Figure 2 The research framework

\section{Experiment Setup and Data Collection}

The experiment setup and data collection are an essential part of the process to attain the EEG signal. The experiment involved 34 subjects, 17 of them were males and the remaining were females. The subjects who took part in this study were within the aged of 19 to 30 years old. There was no significant difference in emotional responses based on gender, although females subjects are inclined to have stronger emotion compared to their male counterparts as described by Akkermans et al. (2018) [28]. A total of 20 minutes was spent for each experiment. The 20 minutes allocated for each session per person was fully utilized by playing the pop-punk and baby rhythm music for four minutes each. Both pop-punk and baby rhythm music were alternately played and listened to by the subjects until the 20 minutes session ended. Data was gathered from 9 AM to 5 PM. Poppunk and baby rhythm were chosen because of the 
capability to describe human emotion and the stress condition. Moreover, these types of music are able to differentiate and identify the EEG signal. The Emotiv Epoc+ device transmits wireless data was used to capture the EEG signal online while EmotivPro software was used to capture for EEG signal recorded offline. However, during the data recording process, the room must be in a quite condition. The subject was asked to relax on the chair. It was also ensured that subjects body movements were minimized until the experiment completed. In addition, the subjects were also required to answer a self-assessment questionnaire before the experiment began. Figure 3 illustrates the relax sitting position of a subject during the experiment.

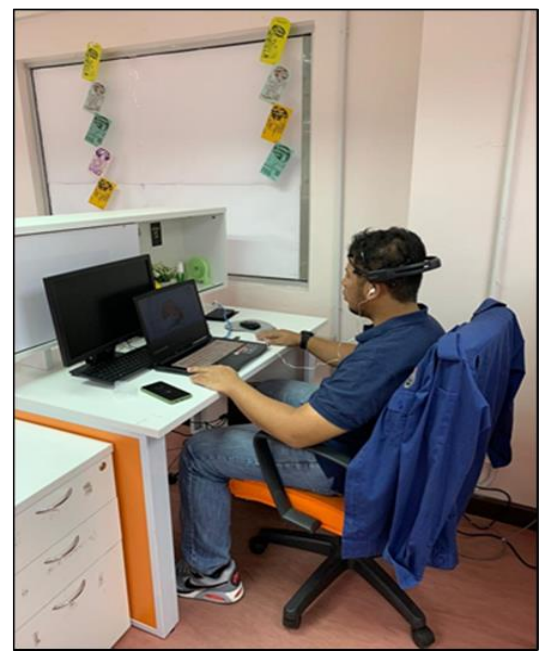

Figure 3 Subject position during the data collection

\section{Features Extraction}

Signal processing is a critical part of removing the noise and the unwanted interrupted signal in that specified EEG signal. The bandpass filter technique is proposed to remove the noise and eliminate the lowest and highest frequency signal. The pure EEG signal is -obtained is in the ranged of $-100 \mu \mathrm{V}$ to 100 $\mu V$. The EEG signal monitors and analyses the spontaneous brain functions in signal activity over some time from electrodes location on the scalp region. This study allows the ten targeted channels (AF3, F7, F3, FC5, T7, AF4, F4, F8, FC6, and T8) to analyse the signal characteristics. The four frequency bands of the delta, theta, alpha, and beta were measured for each electrode channel. Each frequency band contained different features describe in Table 1 below.
Table 1 Frequency band description

\begin{tabular}{|c|c|c|}
\hline $\begin{array}{c}\text { Frequency } \\
\text { type }\end{array}$ & $\begin{array}{l}\text { Frequency } \\
\text { band }(\mathrm{HZ})\end{array}$ & State Condition \\
\hline Delta & $0-4$ & Unconscious state \\
\hline Theta & $4-8$ & State of quiet focus \\
\hline Alpha & $8-13$ & Relaxing and awake \\
\hline Beta & $12-25$ & $\begin{array}{c}\text { Anxious, thinking, } \\
\text { concentration condition, and } \\
\text { awake }\end{array}$ \\
\hline
\end{tabular}

The EEG signal activity can be measured and interpreted in many ways similar to feature extractions. The feature extractions can be presented in a single analysis domain, either time or frequency or combination of the domains for optimal performance [27]. The functions of feature extraction in this study are to analyze the effectiveness of processing and analyzing EEG signals in the frequency domain and time-frequency domain analysis. The Power Spectral Density (PSD) method is applied in the frequency domain while the Continuous Wavelet Transform (CWT) and Short Time Fourier Transform (STFT) method is applied in the timefrequency domain. In a frequency domain, applied Power Spectral Density (PSD) method is used to identify the EEG power signal distribution. For the time-frequency domain, the distribution of EEG energy signals is identified using CWT and STFT approach. Next, twenty-one features extraction EEG signals such as mean, standard deviation, variance, skew, and kurtosis could also be determined.

\section{Arousal and Valence}

Twenty-one features are used to improve the significance of feature extraction results in arousal and valence index formula value. The twenty-one features extraction are used for each delta, theta, alpha, and beta. The features extraction are minimum, maximum, mean, standard deviation, RMS, standard deviation error, median, mean deviation, coefficient mean deviation, variance, skew, kurtosis, entropy, power relative, cross power, magnitude coherence, Hjorth, REE, MSE error and MSE variance. Arousal and valences parameter refer to the physiological activity which contributes to the application of the four-frequency band for investigating the responses of attention, alertness, concentration and relaxation factors in a brain region. The equation of arousal in Equation 1 and valence index formula in Equation 2 are expressed below.

Arousal index formula $=(a+\beta) /(\delta+\theta)$

Valence index formula $=(a+\beta)-(\delta+\theta)$ 


\section{$M C C$ and MCCA}

The features arousal and valence index result become the MCC and MCCA equation's input parameters in order to achieve the study objective. The parameter of the MCC and MCCA equation is consists of true positive (TP), true negative (TN), false positive (FP), and false-negative (FN). The TP is the number of the used EEG selected electrode channels, and TN is the number of unused EEG electrode channels. The FP is a false positive value of arousal and valence in a positive value recognized in the EEG signal, while $\mathrm{FN}$ is a false negative value in arousal and valence recognized in the EEG signal. The six sigma's function is to improve the model performance in equation parameter. Therefore, this function is applied in MCCA equation to gain the best performance and the most accurate result. In the MCCA equation, the parameter value for $\mathrm{FPa}$ is a six-sigma value of arousal and valence in a positive value recognized in the EEG signal. At the same time, $\mathrm{FNa}$ is a six sigma of arousal and valence in the negative value identified in the EEG signal. A previous research conducted by Chen et al. (2019) [29] found that the Six Sigma element in Six Sigma Quality Index (SSQI) in fuzzy environment was used to improve the measurement result. It also states that the Six sigma approach can be used to solve engineering problem. Hence, this is the most suitable, justification of the six-sigma approach in arousal and index data since this method is best use to measure and improve the uncertainty in data processing. The parameter is used to perform the MCC and MCCA equation as mention in equation 3 and 4 . In order to obtain the FP with a positive value and FN with a negative value from the arousal and valence index formula, the TP requires 10 used electrode channels and $\mathrm{TN}$ is 4 unused electrode channels.

$$
M C C=\frac{T P \times T N-F P \times F N}{\sqrt{(T P+F P)(T P+F N) T N+F P)(T N+F N)}}
$$

The major contribution for MCCA equation development for the FPa is a false positive value and $\mathrm{FNa}$ is a false negative value gained from the sixsigma calculation.

$\mathrm{FPa}$ (False Positive) $=$ (Arousalfp/Valencefp index value $)^{6}$

$\mathrm{FNa}$ (False Negative) $=\left(\right.$ Arousalf $_{\mathrm{F}} /$ ValencefN index value $)^{6}$

$$
M C C A=\frac{T P \times T N-F P_{a} \times F N_{a}}{\sqrt{\left(T P+F P_{a}\right)\left(T P+F N_{a}\right)\left(T N+F P_{a}\right)\left(T N+F N_{a}\right)}}
$$

\subsection{RESULTS AND DISCUSSION}

This section explains in details the results of this study obtained from the investigation method and technique applied to enhance the Matthew correlation coefficient (MCC) parameter equation based on false positive and false negative values. The improvement is by using Matthew correlation coefficient advanced (MCCA) which presence in the accuracy percentage to reach $95 \%+5 \%$ in the frequency domain and time-frequency domain analysis. The first part is to identify the features function in EEG signal. The PSD features are presented as the power value in the frequency domain. The CWT and STFT perform the energy distribution value in the time-frequency domain. The effectiveness of power and energy value is defined by manipulating the value into multiple features. The employed of statistical features describe mean is basic result to calculate standard deviation, variance, skewness, and kurtosis. Other features such as, peak the peak value of minimum and maximum as an input to measure the median value to observe the quantities of features distribution.

The power concentration performance was found in power relative, entropy, magnitude square coherence, and magnitude across power spectral density in the frequency domain as approach methods. As a result, the value of power concentration from these features combines to be an input for the arousal and valence index value. Furthermore, the probability density function is measured from the entropy features. The implementation of entropy and Recursive Energy Efficiency (REE) features was used to analyze the signal energy concentration in an existing concentration of the signal energy result for the timefrequency domain. The Hjorth mobility and complexity features describe as a statistical property of signal to analyze the complexity of EEG signal in the frequency domain and time-frequency domain. the approach of Hjorth mobility and complexity features also applied in Emotion detection from EEG recording was found by Liu et al. (2016) [30]. Therefore, all the features mention are used to improve the significance of feature extraction results and investigate arousal and valence index values

Arousal and valence index value is defined as an instantaneous emotion indicator. The arousal indicates the strength of emotion and valence indicates a positive and negative degree of emotion. The strength of emotion describes the emotional intensity ranging from calm to activated emotion such as anger, sadness, happiness, and love, while the degree of positivity and negativity of emotion ranging from pleasant to unpleasant in the classification of emotion is stated by Al-Nafjan et al. (2018) [31]. The arousal and valence are also shown in axis form as described according to the position and level of arousal and valence condition as shown in Figure 4. These arousal and valence values could 
identify the accuracy performance by implementing them into MCC and MCCA equations.

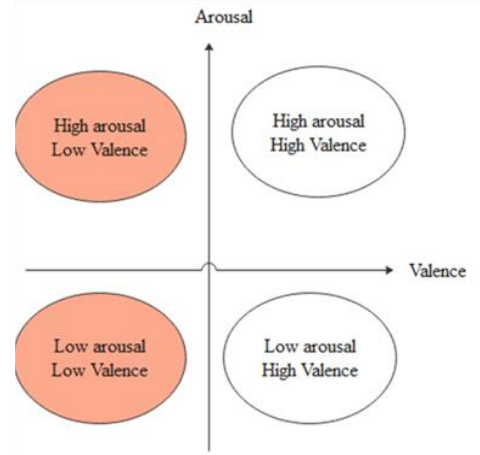

Figure 4 The position and level of arousal and valence condition

According to the features extraction result, arousal and valence are utilized to be applied in the frequency and time-frequency domain. As stated in section, arousal and valence index formula refers to the selected frequency band used in this equation namely: the delta, theta, alpha, and beta frequency band. The optimal arousal and valence results in the frequency band could be applied in the mathematical division method, whereas the combination of alpha and beta is divided by delta and theta. The combination of alpha and beta is created due to the same physiological signal characteristics such as awake, attention, and concentration. In contrast, delta and theta usually occurs in drowsiness, fatigue, and unconscious states according to Shang et al. (2019)[32]. The arousal and valence index results are obtained from the sum of features value based on chosen frequency band which becomes the second part in achieving the aim of this study. The arousal and valence optimal result was found possible in measuring the MCC and MCCA accuracy performance and demonstrated in frequency and time-frequency domain. The measure of multimodal result is indicated to be calculated in MCC2, MCC4, and MCCA. The MMC2 is the multiple 2 from false-positive and false-negative from arousal and valence index while MCC4 is multiple four of it. Both multiplication techniques perform insufficient accuracy results. Therefore, MCCA is established to improve the Multimodal accuracy performance in percentages. The MCCA result obtained was from six multiplication of false-positive and false-negative. In line with the finding of multimodal value for frequency domain and time-frequency domain, it was found that MCCA is the best multimodal performance. The multimodal performance of arousal and valence results for frequency domain display in Table 2 and Table 3.
Table 2 Multimodal accuracy performance for frequency domain for arousal in percentage

\begin{tabular}{lcll}
\hline Condition & MCC2 & MCC4 & MCCA \\
\hline $\begin{array}{l}\text { Resting } \\
\text { state }\end{array}$ & 29.76 & 57.11 & 99.4 \\
Music 1 & 81.89 & 35.06 & 98.50 \\
Music 2 & 93.63 & 14.50 & 98.28 \\
\hline
\end{tabular}

Table 3 Multimodal accuracy performance for frequency domain for valence in percentage

\begin{tabular}{lccc}
\hline Condition & MCC2 & MCC4 & MCCA \\
\hline $\begin{array}{l}\text { Resting } \\
\text { state }\end{array}$ & 20.47 & 53.97 & 99.33 \\
Music 1 & 20.45 & 53.77 & 99.10 \\
Music 2 & 14.53 & 72.27 & 99.38 \\
\hline
\end{tabular}

The arousal and valence for the time-frequency domain that are used to express the multimodal performance were calculated by applying the multimodal equation. The ability of the MCCA parameter in the multimodal equation to improve the performance is taken into consideration and expected to be proven in Table 4 and Table 5.

Table 4 Multimodal performance for time-frequency domain for arousal in percentage

\begin{tabular}{lcccccc}
\hline Condition & \multicolumn{2}{c}{ MCC2 } & \multicolumn{2}{c}{ MCC4 } & \multicolumn{2}{c}{ MCCA } \\
& CWT & STFT & CWT & STFT & CWT & STFT \\
& & & & & & \\
\hline $\begin{array}{l}\text { Resting } \\
\text { state }\end{array}$ & 61.39 & 12.57 & 51.85 & 11.60 & 99.12 & 99.70 \\
Music 1 & 92.05 & 93.46 & 12.28 & 14.25 & 98.43 & 99.88 \\
Music 2 & 74.54 & 12.57 & 11.06 & 11.60 & 98.18 & 99.70
\end{tabular}

Table 5 Multimodal performance for time-frequency domain for valence in percentage

\begin{tabular}{lcccccc}
\hline Condition & \multicolumn{2}{c}{ MCC2 } & \multicolumn{2}{c}{ MCC4 } & \multicolumn{2}{c}{ MCCA } \\
& CWT & STFT & CWT & STFT & CWT & STFT \\
& & & & & & \\
\hline $\begin{array}{l}\text { Resting } \\
\text { state }\end{array}$ & 11.98 & 84.62 & 24.76 & 53.86 & 99.03 & 99.20 \\
Music 1 & 62.28 & 85.22 & 90.25 & 40.32 & 99.62 & 98.14 \\
Music 2 & 20.50 & 59.13 & 54.48 & 41.77 & 99.94 & 99.86 \\
& & & & & & \\
\end{tabular}

The arousal of MCC and MCCA in three conditions (resting state, pop-punk (music 1), and baby rhythm (music 2)) shows a noticeable increase with the highest result of MCC which is $12.03 \%$ and the MCCA is $99.4 \%$ as shown in Figure 5. The six-sigma concept is implemented in MCCA is the major contributing factor that has caused in the increased of the accuracy percentage factor. In general, six sigma's serves the function to improve the model performance in large data sizes applied for multivariable purposes [29]. It found that the six-sigma approach produces a maximum quality result inaccuracy. The finding of this method has also been 
applied at the valence index and it appears to meet the study expectations. Another reason which has caused a growing percentage in valence is the extra connectivity that occurs between the electrode pair. The valence results in Figure 6 shows the high percentage of MCC accuracy known in the valence graph presents $97.17 \%$ for MCC and $99.39 \%$ for MCCA as expected. The high accuracy of valence obtained indicates that the emotional state is highly detected. The six-sigma parameter in the arousal and valance index is used in the MCCA equation for techniques due to the expected result performance.

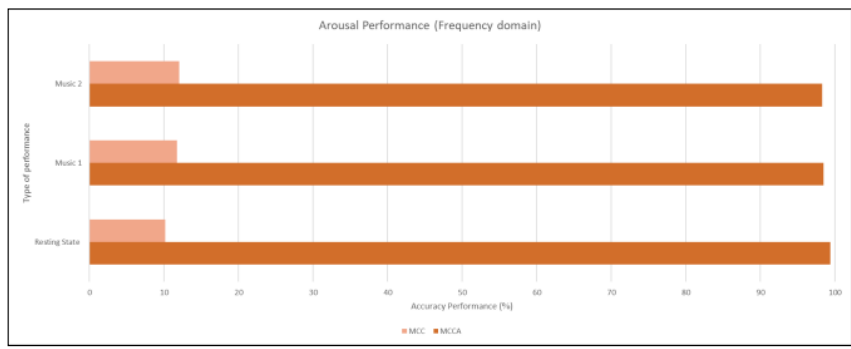

Figure 5 Arousal MCC performance in the frequency domain

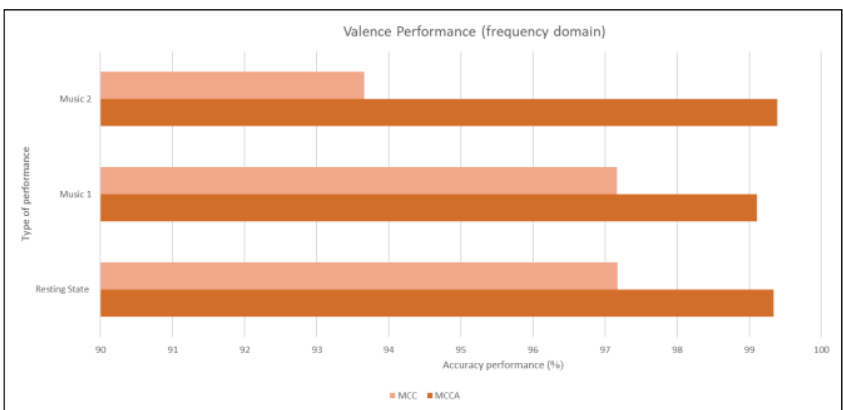

Figure 6 Valence MCC performance in the frequency domain

Arousal index value presents the human emotion and relaxation and valence related to the positive and negative degree of emotion in EEG signal. The arousal index is emotional states involving fewer electrode pairs compared with the valence index with high electrode pair connectivity. The timefrequency domain diversified the CWT and STFT method energy value to gain the required features to obtain the result's arousal and valence index. The arousal and valence index value in the timefrequency domain applies to the MCC and MCCA equation parameters. The MCC arousal accuracy performance produces a low percentage (12.8\%) compared to the MCCA percentage $(99.8 \%)$ with a substantial difference of more than $80 \%$. As a result, the accuracy percentage result of arousal in timefrequency domain in MCCA is successfully achieved the objective of this study which is proven in Figure 7. In Figure 8, the MCCA shows that most of the highest accuracy percentage compared to MCC with the difference in percentage is $\pm 11 \%$. However, the MCC percentage is not sufficient to achieve the objective of the study. Therefore, the MCCA is required in the valence index to improve the accuracy percentage. From the improvement, the result of the highest MCCA accuracy is $99.9 \%$ and reached the objective. The result was directly compared with the previously reported finding on a summary of the highest performance of MCC and MCCA in Figure 7 and Figure 8.

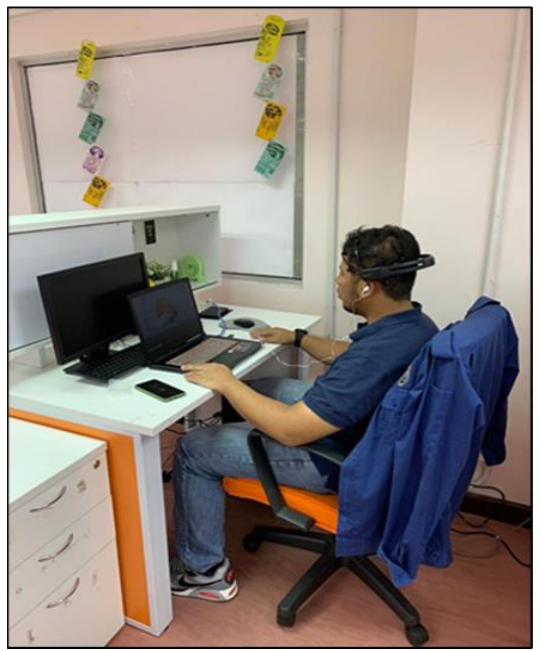

Figure 7 Arousal MCC performance in the time-frequency domain

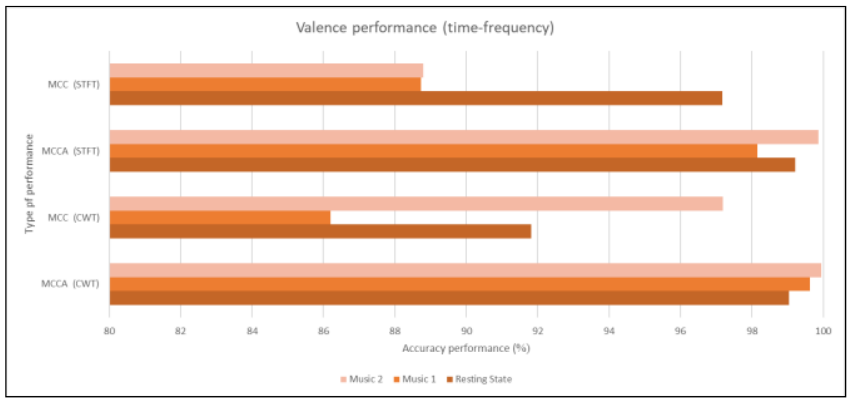

Figure 8 Valence MCC performance in the time-frequency domain

\subsection{CONCLUSION}

In conclusion, this paper found the best performance accuracy percentage result from arousal and valence for MCC which is $93.63 \%$ and MCCA is $99.88 \%$. The results indicate that these accuracy percentage gaps arise due to the impact of connectivity electrode pair as the arousal index has fewer connectivity than the valence index. Nevertheless, this could potentially lead to future study of connectivity electrode pair effected by enhancing the parameter capabilities and the extraction of signal features. Based on the research finding of accuracy performance results, MCC equation is still justifiable to be applied by using parameter of arousal and valence index. 
Interestingly, a higher accuracy percentage could be achieved using the enhancement of the MCC equation. The data of this study suggests that MCCA equation which derived from existing MCC equation could enhance the accuracy percentage for arousal and valence index.

\section{References}

[1] A. Mofredj, S. Alaya, K. Tassaioust, H. Bahloul, and A. Mrabet. 2016. Music Therapy, A Review of the Therapeutic Benefits for Critical III. J. Crit. Care. 1-22.

[2] G. Nave, J. Minxha, D. M. Greenberg, M. Kosinski, D. Stillwell, and J. Rentfrow. 2018. Musical Preferences Predict Personality: Evidence From Active Listening and Facebook Likes. Assoc. phychological Sci. 1-14.

[3] K. Banerjee, T. Guhathakurta, R. Sengupta, D. Ghosh, and P. Ghose. 2016. Study on Brain Dynamics by Non Linear Analysis of Music Induced EEG Signals. Phys. A Stat. Mech. its Appl. 444: 110-120.

[4] A. M. Bhatti, M. Majid, S. M. Anwar, and B. Khan. 2016. Human Emotion Recognition and Analysis in Response to Audio Music Using Brain Signals. Comput. Human Behav. 65: 267-275.

[5] D. M. Greenberg, S. Baron-Cohen, D. J. Stillwell, M. Kosinski, and P. J. Rentfrow. 2015. Musical Preferences are Linked to Cognitive Styles. PLoS One. 10(7): 1-22.

[6] M. K. Bashar, I. Chiaki, and H. Yoshida. 2016. Human Identification from Brain EEG Signals Using Advanced Machine Learning Method. Cofn. 2016 IEEE EMBS Conference on Biomedical Engineering and Sciences (IECBES). 475-479.

[7] M. Li and M. Henry. 2016. Complex Bandpass Filtering for Coriolis Mass Flow Meter Signal Processing. IECON Proc. (Industrial Electron. Conf. 2: 4952-4957.

[8] J. Baranowski and P. Piątek. 2017. Fractional Band-Pass Filters: Design, Implementation and Application to EEG Signal Processing. J. Circuits, Syst. Comput. 26(11): 1-21.

[9] R. Boostani, F. Karimzadeh, and M. Nami. 2017. Computer Methods and Programs in Biomedicine a Comparative Review on Sleep Stage Classification Methods in Patients and Healthy Individuals. Comput. Methods Programs Biomed. 140: 77-91.

[10] Y. Shoji, C. R. Patti, and D. Cvetkovic. 2017. Electroencephalographic Neurofeedback to up-Regulate Frontal Theta Rhythms: Preliminary Results. Proc. Annu. Int. Conf. IEEE Eng. Med. Biol. Soc. EMBS. 1425-1428.

[11] R. T. Toll, W. Wei, S. Naparstek, Y. Zhang, M. Narayan, B. Patenaude, D. Abuamara, K. Sarhadi, C. Cornelssen, C. Marmar and A. Etkin. 2020. An Electroencephalography Connectomic Profile of Posttraumatic Stress Disorder. Am. J. Psychiatry. 14:1-11.

[12] N. Gursel Ozmen, L. Gumusel, and Y. Yang. 2018. A Biologically Inspired Approach to Frequency Domain Feature Extraction for EEG Classification. Comput. Math. Methods Med. 2018: 19-24.

[13] D. Dilber and J. Kaur. 2017. EEG Based Detection of Epilepsy by a Mixed Design Approach. 2016 IEEE Int. Conf. Recent Trends Electron. Inf. Commun. Technol. RTEICT 2016 - Proc. 1425-1428.

[14] Y. Yang, Q. Wu, M. Qiu, Y. Wang, and X. Chen. 2018 Emotion Recognition from Multi-Channel EEG through Parallel Convolutional Recurrent Neural Network. Proc. Int. Jt. Conf. Neural Networks. 2018-July: 352-359.

[15] R. Fernandez Rojas, X. Huang, and K. L. Ou. 2019. A Machine Learning Approach for the Identification of a Biomarker of Human Pain using fNIRS. Sci. Rep. 9(1): 1-12.

[16] R. Ramos-Aguilar, J. A. Olvera-López, I. Olmos-Pineda, and
S. Sánchez-Urrieta. 2020. Feature Extraction from EEG Spectrograms for Epileptic Seizure Detection. Pattern Recognit. Lett. 133: 202-209.

[17] H. He, W. Zhao, and K. Fujimoto. 2019. Identification of EEG-based Music Emotion using Hybrid COA Features and t-SNE. ACM Int. Conf. Proceeding Ser. 95-102.

[18] M. T. Omid Dehzangi. 2019. EEG Based Driver Inattention Identification via Features Profiling and Dimensionality Reduction. Adv. Body Area Netw. I. 107-121.

[19] H. Jebelli, M. Mahdi Khalili, and S. Lee. 2019. A Continuously Updated, Computationally Efficient Stress Recognition Framework Using Electroencephalogram (EEG) by Applying Online Multitask Learning Algorithms (OMTL). IEEE J. Biomed. Heal. Informatics. 23(5): 1928-1939.

[20] Z. Halim and M. Rehan. 2020. On Identification of Drivinginduced Stress using Electroencephalogram Signals: A Framework based on Wearable Safety-critical Scheme and Machine Learning. Inf. Fusion. 53(May 2018): 66-79.

[21] E. J. Choi and D. K. Kim. 2018. Arousal and Valence Classification Model Based on Long Short-term Memory and DEAP Data for Mental Healthcare Management. 24(4): 309-316.

[22] N. Thammasan, K. I. Fukui, and M. Numao. 2017. An Investigation of Annotation Smoothing for EEG-based Continuous Music-emotion Recognition. 2016 IEEE Int. Conf. Syst. Man, Cybern. SMC 2016 - Conf. Proc. 33233328.

[23] A. Mert and A. Akan. 2018. Emotion Recognition based on Time-frequency Distribution of EEG Signals using Multivariate Synchrosqueezing Transform. Digit. Signal Process. A Rev. J. 81: 106-115.

[24] X. Hu, F. Li, and J. T. D. Ng. 2018. On the Relationships between Music-induced Emotion and Physiological Signals. Proc. 19th Int. Soc. Music Inf. Retr. Conf. ISMIR 2018. 362-369.

[25] S. Patidar, R. B. Pachori, A. Upadhyay, and U. Rajendra Acharya. 2017. An Integrated Alcoholic Index using Tunable-Q Wavelet Transform based Features Extracted from EEG Signals for Diagnosis of Alcoholism. Appl. Soft Comput. J. 50: 71-78.

[26] S. Patidar and T. Panigrahi. 2017. Detection of Epileptic Seizure using Kraskov Entropy Applied on Tunable-Q Wavelet Transform of EEG Signals. Biomed. Signal Process. Control. 34: 74-80.

[27] A. Arunkumar, R.K. Ramkumar, V.V. Venkatraman, E. Abdulhay, S. L. Fernandes, S. Kadry and S. Segal. 2017. Classification of Focal and Non Focal EEG using Entropies. Pattern Recognit. Lett. 94: 112-117.

[28] J. Akkermans, R. Schapiro, D. Müllensiefen, K. Jakubowski, D. Shanahan, D. Baker, V. Busch, K. Lothwesen, P. Elvers, T. Fischinger, K. Schlemmer and K. Frieler. 2018. Decoding Emotions in Expressive Music Performances: A Multi-lab Replication and Extension Study Replication and Extension Study. Cogn. Emot. 1-20.

[29] K. Chen, C. Wang, K. Hua, and S. Chiu. 2019. International Journal of Production Economics Developing One-sided Specification Six-sigma Fuzzy Quality Index and Testing Model to Measure the Process Performance of Fuzzy Information. Intern. J. Prod. Econ. 208(57): 560-565.

[30] J. Liu, H. Meng, A. Nandi, and M. Li. 2016. Emotion Detection from EEG Recordings. 2016 12th Int. Conf. Nat. Comput. Fuzzy Syst. Knowl. Discov. ICNC-FSKD 2016. 17221727.

[31] A. Al-Nafjan, M. Hosny, A. Al-Wabil, and Y. Al-Ohali. 2017. Classification of Human Emotions from Electroencephalogram (EEG) Signal using Deep Neural Network. Int. J. Adv. Comput. Sci. Appl. 8(9): 419-425.

[32] Z. Shang, Y. Zhao, and Y. Lian. 2019. Low Power FIR Filter Bank for EEG Processing Using Frequency-Response Masking Technique. Int. Conf. Digit. Signal Process. DSP. 2018-Novem. 1-5. 